\title{
Influence of circulating pump efficiency on the heat exchange process in a plate heat exchanger used in a solar heating installation
}

\author{
Pawet Obstawski ${ }^{1},{ }^{*}$, Tomasz Bakoń ${ }^{1}$, and Anna Kozikowska ${ }^{1}$ \\ ${ }^{1}$ Warsaw University of Life Sciences, Faculty of Production Engineering, Department of \\ Fundamental Engineering, Nowoursynowska 166, 02-787 Warszawa, Poland
}

\begin{abstract}
In solar heating systems with an absorber area of more than 20 $\mathrm{m}^{2}$, a plate heat exchanger is used as a separator between the primary glycol-based refrigerant and secondary water. The use of a plate heat exchanger enables an increase in the heat exchange area compared to the standard coil heat exchangers located inside the domestic hot water tank. An important problem is to determine the volume flow rate on both the primary and secondary side of the exchanger. The paper presents an analysis of the influence of the circulation pump efficiency on the primary and secondary side of the heat exchanger installed in a solar heating installation on the intensity of the heat exchange process.
\end{abstract}

\section{Introduction}

A plate heat exchanger is used as a separator for the exchange of heat between two different working media. In solar heating installations, the plate heat exchanger is used as a separator between a collector bank connected to the primary side of the heat exchanger, where the working medium is a propylene glycol-based refrigerant, and a domestic hot water storage tank (DHW) connected to the secondary side of the heat exchanger that constitutes a thermal load for solar collectors. This solution is usually adopted in the case of large solar heating installations. A large solar heating installation should be understood as the system where the aperture area of collectors is larger than $20 \mathrm{~m}^{2}$. The use of an external plate heat exchanger instead of a DHW storage tank with a coil heat exchanger allows for virtually unlimited selection of heat exchange surfaces. In this manner, it is possible to increase the amount of transferred solar energy accumulated through the aperture of collectors and, consequently, to reduce the time required for hot water production. Implementation of such a solution does not always lead to reduction in the time for hot water production. Reducing the time needed to produce domestic hot water requires continuous control over the heat exchange process between the primary and secondary sides of the heat exchanger. To this end, it is necessary to analyze dynamic properties of the heat exchange process in the plate heat exchanger.

\footnotetext{
*Corresponding author: pawel_obstawski@sggw.pl
} 


\section{Determining dynamic properties of plate heat exchangers}

Despite the fact that plate heat exchangers are widely used, and their design is very well known, both simulation and operational tests of the heat exchange process have been carried out continually. This stems from the fact that the heat exchange process, taking place in the plate heat exchanger, is very complicated. Dynamics of the heat exchange process is influenced by various design factors, e.g. the material used for construction of the exchanger plate, plate profile, as well as operational factors, such as: thermal input power, efficiency, flow resistance of the medium and hydraulic system diameters [1-3]. Therefore, research works concern mainly design solutions aimed at improving the irregularity of medium flow through the exchanger channels and reducing the flow resistance through the exchanger channels [4-6]. There are also simulation studies on the heat exchange process which are carried out with the use of innovative IT tools [7-8]. Based on the results achieved, it should be concluded that the intensity of heat exchange process is mainly influenced by: the volume flow of the medium on the primary and secondary sides of the heat exchanger as well as the thermal conductivity coefficient of the material from which the heat exchanger is made [9]. The thermal conductivity coefficient is determined experimentally based on a modified Wilson's method [10], however, studies are being conducted to develop new methods for determining the thermal conductivity coefficient of the heat exchanger under operating conditions [11-12]. During the heat exchanger operation, the most important is the amount of heat exchanged between the primary and secondary sides at a specific design point. The intensity of heat exchange process depends on dynamic properties of the heat exchanger at a given design point and on the volume flow rate on the primary and secondary sides of the heat exchanger which is influenced by the control algorithm applied. Hence, it is important to determine dynamic properties of the heat exchanger. Usually, they are analyzed by means of models based on differential equations combining design parameters. They allow for determination of dynamic properties at the design stage. There are also other methods which are based on first order differential equations derived from the energy balance [13-14].

Laplace transform [15] is often used to solve the differential equation describing the transient state of the heat exchanger. Diagnostics of the plate heat exchanger based on the analysis of step response allows to determine the influence of the circulating pump efficiency on temperature rise. Such an analysis is necessary for correct design of the automatic control system ensuring intensive heat exchange under steady and transient states.

Determination of dynamic properties of the heat exchanger becomes more complicated, if we want to carry it out under operating conditions, since in the case of stochastic disturbances affecting the power flux on the hot and cold sides of the heat exchanger, as is the case with solar heating installations, the heat exchanger is operating continuously under transient states. It should be noted that operating parameters of the heat exchanger under transition states may change their values, and thus, the heat exchanger, operated under operating conditions, is a non-stationary facility [16]. This demonstrates that operating parameters may be different from those assumed at the design stage. This means that, in most cases, the effect of volume flow rate on the primary and secondary sides of the heat exchanger on the intensity of heat exchange process has to be estimated based on experiments carried out under operating conditions. 


\section{Description of the test stand}

The problem will be discussed on the example of operating data recorded during operation of two solar heating installations based on flat-plate and vacuum liquid collectors with the same aperture area of $10 \mathrm{~m}^{2}$. Both flat-plate and vacuum liquid collectors are mounted on a free-standing structure oriented southwards. The inclination angle of both flat-plate and vacuum collectors is the same and amounts to $40^{\circ}$ to the horizontal.

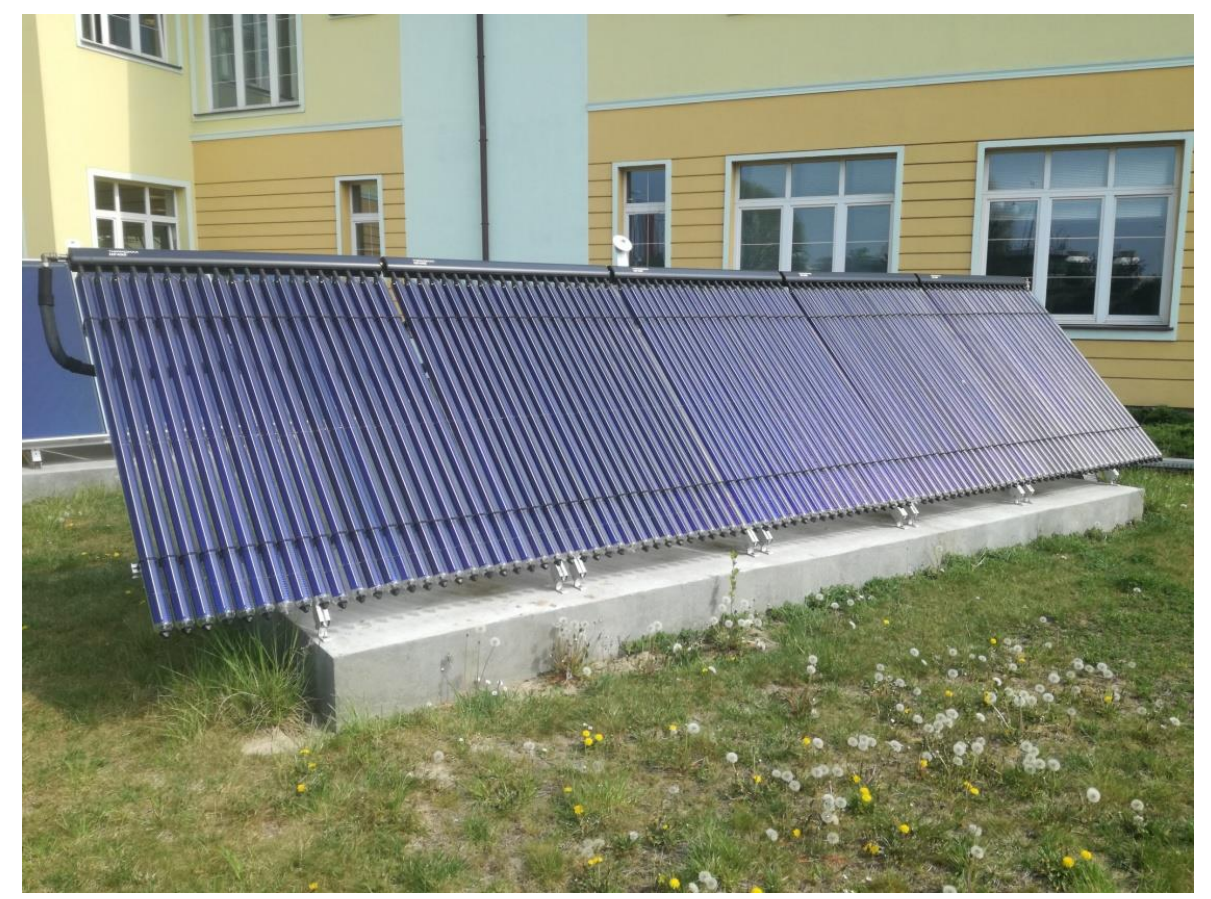

Fig. 1. Solar heating installation.

Buffer storage tanks with a volume of $500 \mathrm{dm}^{3}$ are used as thermal load for flat-plate and vacuum collectors. As separators between the glycol loop (primary side of the heat exchanger) and the water loop (secondary side of the heat exchanger), plate heat exchangers, with a total number of plates coming to 40 pieces, are used in both installations. According to the data sheet, the plate heat exchangers used can transfer up to $70 \mathrm{~kW}$ of power, if the volume flow rate on the primary and secondary sides is adjusted appropriately. In both cases, the primary side of the plate heat exchanger is connected to solar collectors by means of "Spiro" pipes with an internal diameter of $25 \mathrm{~mm}$. The secondary side of heat exchangers is connected to buffer storage tanks by means of galvanized steel pipes with an internal diameter of $25 \mathrm{~mm}$. Both flat-plate and vacuum collector systems are equipped with 25-100 circulating pumps with the possibility of stepless efficiency control by means of a $0-10 \mathrm{~V}$ DC signal. To measure the volume flow, a turbine flow meter is used, which is interoperating with a converter allowing for conversion of the volume flow rate ranging between 0 and $40 \mathrm{dm}^{3}$ into a $4-20 \mathrm{~mA}$ analog signal. To measure the intensity of solar radiation falling on flat-plate and vacuum collectors, class $\mathrm{A}$ pyranometers are used. Temperature is measured with the use of four-wire PT100 resistance temperature detectors. The control algorithm for the entire system is implemented in PLCs. 


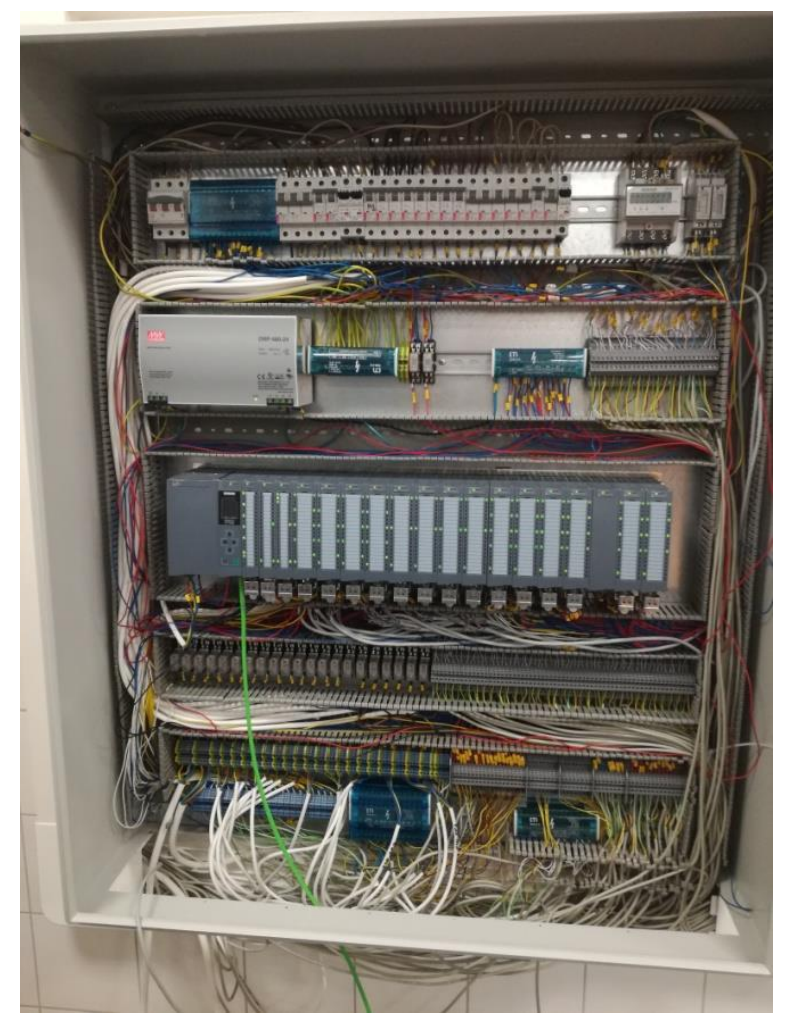

Fig. 2. Control cabinet.

The PLC CPU has been extended by modules dedicated to individual types of measuring transducers used in the installation. The PLC is connected via Ethernet to a PC that is used as the server on which the SCADA system is installed. Data is exchanged between the PLC and SCADA with the use of the Modbus TCP/IP protocol. Such a solution allows for visualization of the system operation, acquisition of measurement data and remote access.

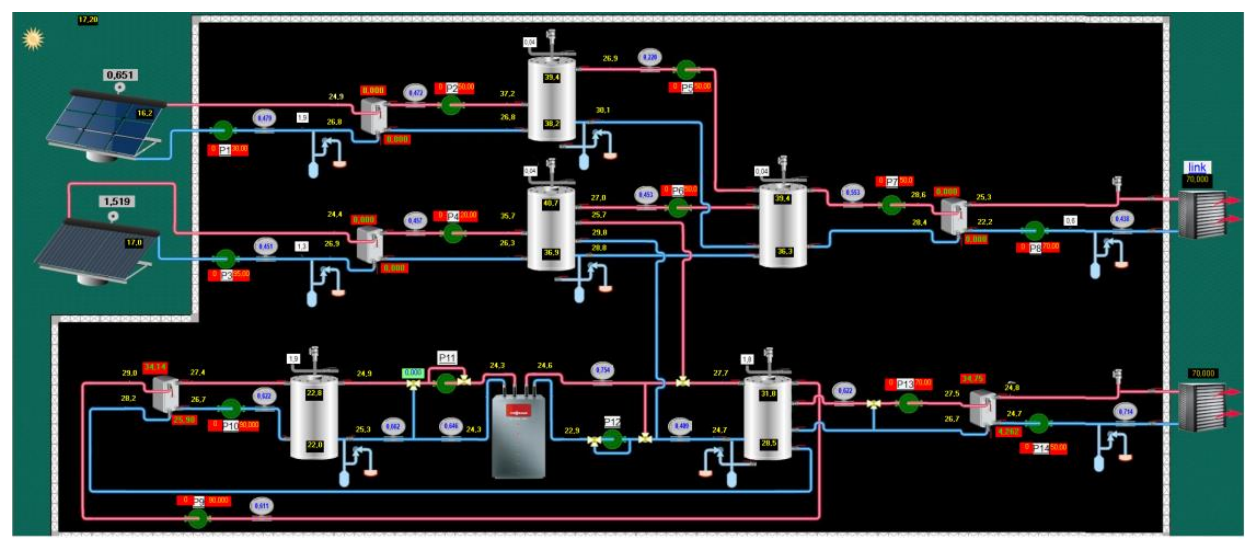

Fig. 3. Visualization of the installation operation. 


\section{Analysis of the influence of circulating pump efficiency on the intensity of heat exchange process in a plate heat exchanger}

As mentioned above, the efficiency of circulating pumps on the primary and secondary sides of the heat exchanger has a considerable influence on the intensity of heat exchange process. Therefore, the range of possible changes in the efficiency of circulating pumps is important, which corresponds to $0 \%$ of the minimum control signal level setpoint and $100 \%$ of the maximum control signal level setpoint. For flat-plate liquid collectors, the minimum circulating pump efficiency on the primary side of the heat exchanger, corresponding to the control signal value of $0 \%$, is $4 \mathrm{l} / \mathrm{min}$, and the maximum value, corresponding to $100 \%$ of the pump setpoint, is $17 \mathrm{l} / \mathrm{min}$. On the secondary side of the plate heat exchanger in the flatplate liquid collector system, the minimum circulating pump efficiency, corresponding to the control signal value of $0 \%$, is $41 / \mathrm{min}$, and the maximum value, corresponding to $100 \%$ of the pump setpoint, is $22 \mathrm{l} / \mathrm{min}$.

For vacuum collectors, the volume flow rate of the refrigerant on the primary side of the heat exchanger is significantly lower, and equals $21 / \mathrm{min}$ for the control signal value of $0 \%$ and $10 \mathrm{l} / \mathrm{min}$ for the control signal value of $100 \%$. For the secondary side of the plate heat exchanger installed in the vacuum collector system, the achievable volume flow rate control range is much larger than the one for the secondary side of the plate heat exchanger installed in the flat-plate collector system, and amounts to: $10 \mathrm{l} / \mathrm{min}$ for the control signal value of $0 \%$ and $25 \mathrm{l} / \mathrm{min}$ for the control signal value of $100 \%$, respectively. It is, therefore, clear that despite mounting of the same plate heat exchangers and circulating pumps on the primary and secondary sides, the achievable control range is different and depends on the sum of pipe and local pressure losses in the installation. The achievable range of volume flow control on the primary side of both installations shows that with a similar length of a pipe connecting flat-plate and vacuum collectors with heat exchangers, vacuum collectors feature much higher pipe pressure losses. This means a considerably smaller achievable volume flow range. Furthermore, if the circulating pump setpoint level on the primary side of the heat exchanger, installed in the vacuum collector installation, is too low, the volume flow rate may also be too low which, in turn, leads to solar system stagnation and faster consumption of propylene glycol-based refrigerant. Such situation is shown in Figure 4. When the set temperature gradient is reached, between the working medium in the solar heating installation and the water in the buffer storage tank, the controller starts the circulating pumps on the primary and secondary sides of the heat exchanger. The heat exchanger secondary side pump set to $70 \%$ performed at a volume flow of $17.5 \mathrm{l} / \mathrm{min}$, while the heat exchanger primary side pump set to $20 \%$, firstly, performed at a flow rate of 7 $1 /$ min which, after compensation of the pressure losses in the installation, dropped to 3 $1 / \mathrm{min}$. Since the volume flow rate was too low, the medium in the collector evaporated which resulted in a further decrease in the volume flow rate in the installation and an increase in the medium temperature. After about 2 minutes, the pump efficiency was increased from $20 \%$ to $70 \%$. As a result of the increase in pump efficiency, pressure increased which resulted in the flow of glycol in liquid phase through the collector and power take-off by the secondary side of the heat exchanger (Fig. 5). The maximum recorded medium temperature was $110^{\circ} \mathrm{C}$ and the glycol flow rate in the solar heating installation stabilized once the glycol temperature dropped below $100^{\circ} \mathrm{C}$ (Fig. 4). On the basis of the presented case, it should be concluded that higher flow resistances on the primary side of the installation narrow down the volume flow control considerably. Furthermore, it should be noted that with a relatively lower flow rate on the primary side of the heat exchanger when compared to the secondary side, the secondary side power of the heat exchanger is higher than the input power supplied by collectors to the primary side. This means that power losses are released from the storage tank to the environment (Fig. 5). 


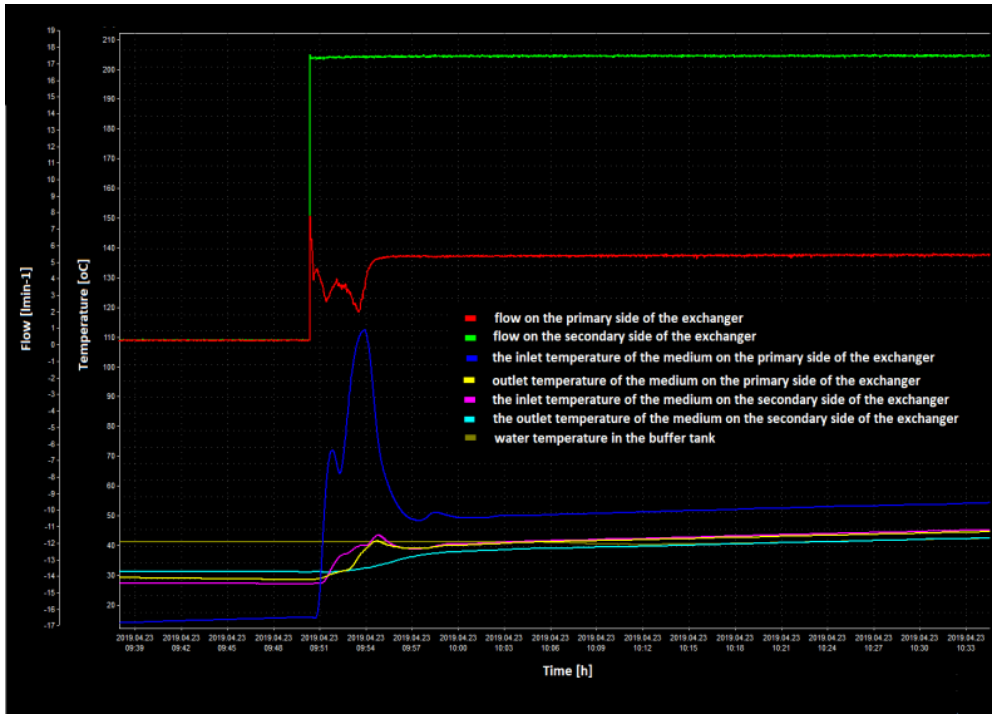

Fig. 4. Overheating of the vacuum collector installation with too low setpoint level for the circulating pump on the primary side of the heat exchanger.

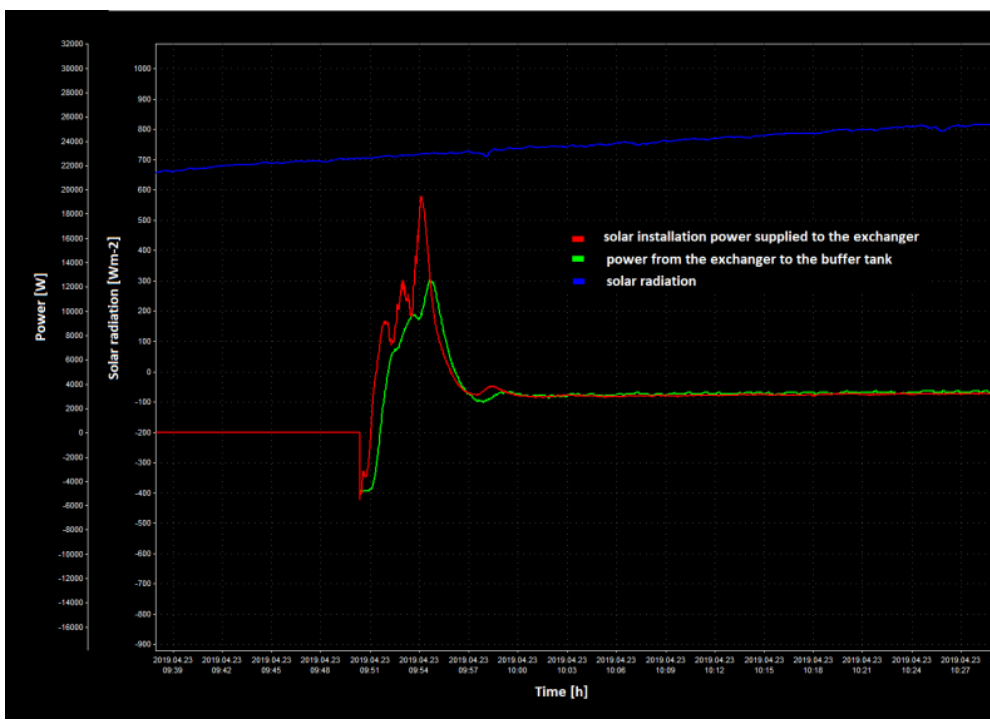

Fig. 5. Power take-off by the secondary side of the heat exchanger once the solar heating installation becomes overheated.

Figure 6 shows the heat exchange process in the plate heat exchanger installed in the vacuum collector installation with the circulating pump setpoint on the primary side of the heat exchanger at the level of $70 \%$ which corresponds to a volume flow rate of $5 \mathrm{l} / \mathrm{min}$, and on the secondary side at the level of 55\% which corresponds to a volume flow rate of 15.5 1/min (for a low solar radiation intensity value: $300-650 \mathrm{~W} / \mathrm{m}^{2}$ ). At higher intensity of solar radiation, the input power supplied by the working medium to the primary side of the heat exchanger is higher than the power taken off by the secondary side. This means that the buffer storage tank is loaded at minimum losses during the heat exchange process taking place in the heat exchanger. However, when the solar radiation intensity falls down, while the water volume flow rate on the secondary side of the heat exchanger is so high that the 
delta between the water inlet and outlet temperatures is very small (Fig. 7), periodic power losses take place from the storage tank to the environment (Fig. 6). This means that at low levels of solar radiation intensity, the volume flow rate on the primary side should be reduced.

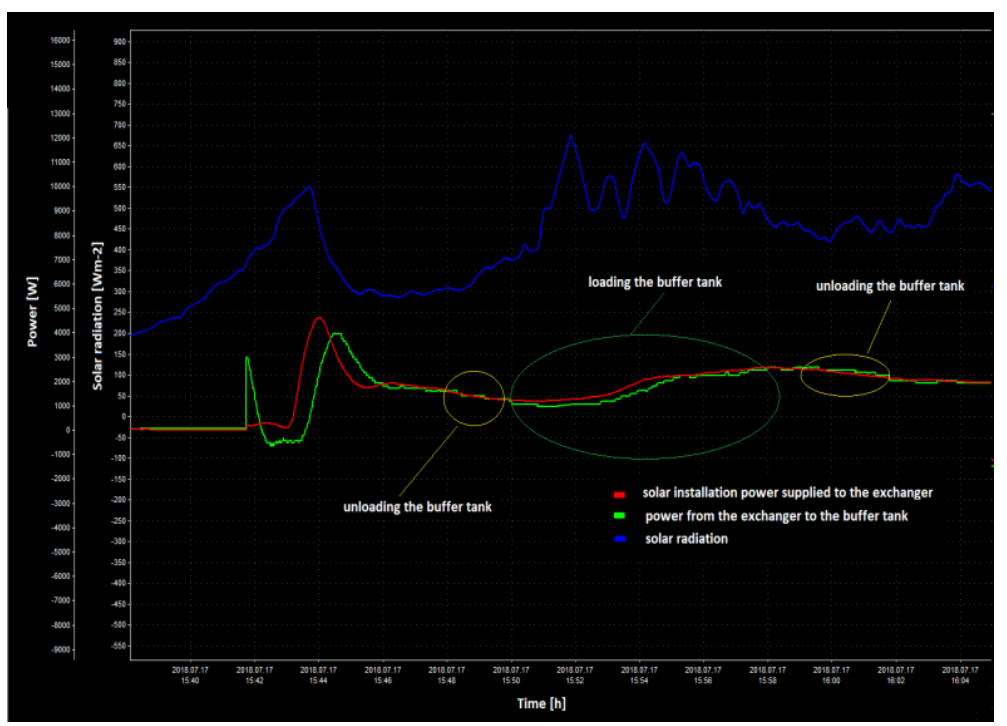

Fig. 6. Power distribution of the primary and secondary sides of the heat exchanger at volume flow rates of $5 \mathrm{l} / \mathrm{min}$ and $15.5 \mathrm{l} / \mathrm{min}$, respectively.

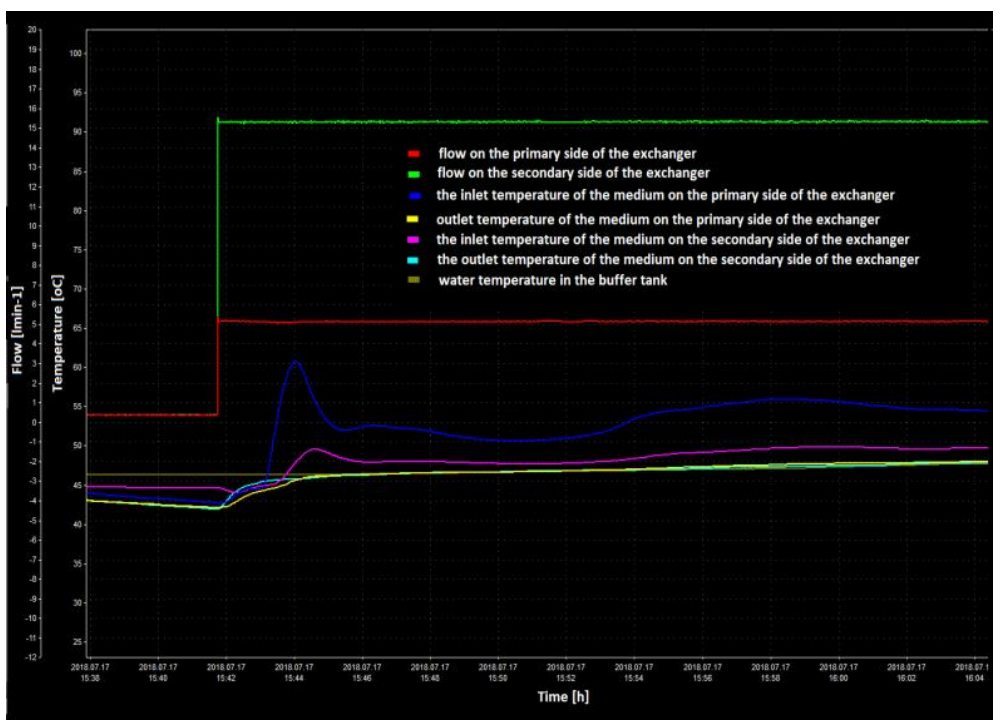

Fig. 7. Temperature distribution on the primary and secondary sides of the heat exchanger at volume flow rates of $51 / \mathrm{min}$ and $15.5 \mathrm{l} / \mathrm{min}$, respectively.

A similar situation can be observed with a higher, when compared to the previous case, volume flow rate on the primary side of the heat exchanger equal to $101 / \mathrm{min}$ which corresponds to $95 \%$ of the circulating pump setpoint, and with the same volume flow rate on the secondary side of the heat exchanger equal to $151 / \mathrm{min}$. An increase in the volume flow rate on the primary side of the heat exchanger led to an increase in the gradient 
between the inlet and outlet temperatures on the secondary side of the heat exchanger (Fig. 9). When analyzing the heat exchange process in the plate heat exchanger, one should notice power fluctuations when the intensity of solar radiation changes. With such a volume flow rate on the primary and secondary sides of the heat exchanger and a reduction in the solar radiation intensity, power losses from the buffer storage tank take place (Fig. 8).

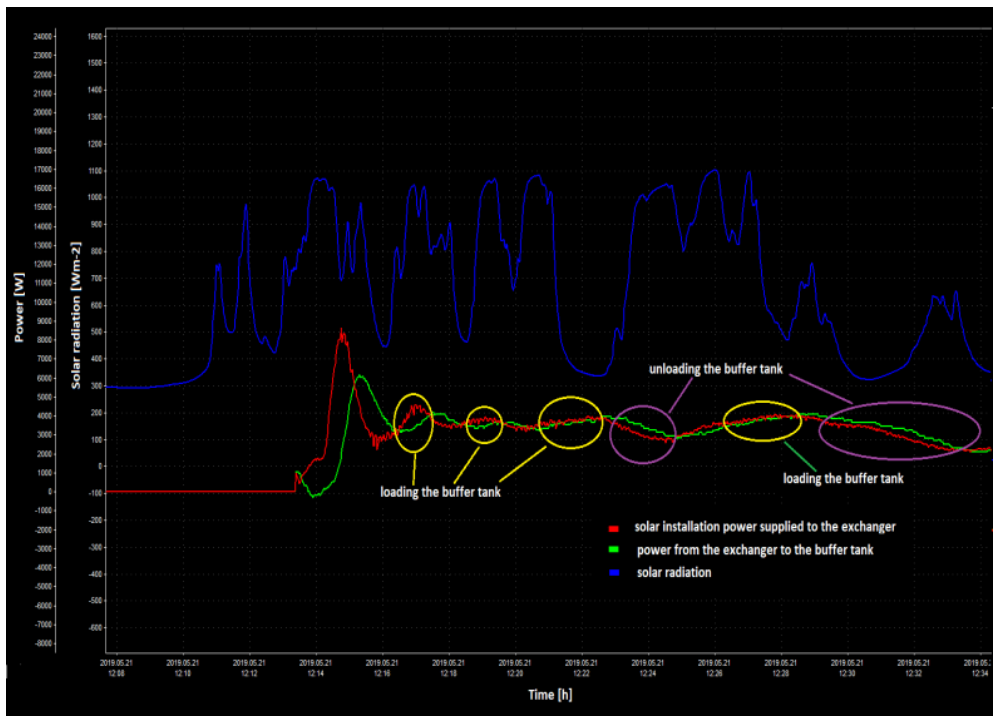

Fig. 8. Power distribution of the primary and secondary sides of the heat exchanger at volume flow rates of $5 \mathrm{l} / \mathrm{min}$ and $15.5 \mathrm{l} / \mathrm{min}$, respectively.

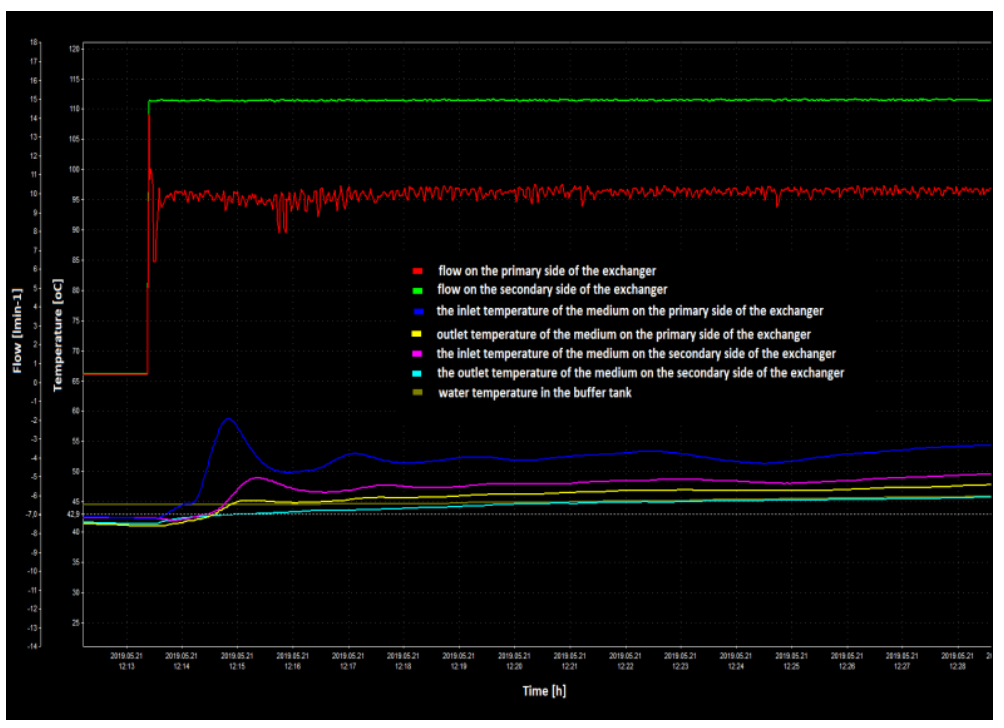

Fig. 9. Temperature distribution on the primary and secondary sides of the heat exchanger at volume flow rates of $51 / \mathrm{min}$ and $15.5 \mathrm{l} / \mathrm{min}$, respectively.

Removal of the adverse effect of dissipating the accumulated heat from the buffer storage tank to the environment, at low levels of solar radiation intensity, is achieved only by introducing a minimum setpoint in the circulating pump on the secondary side of the heat exchanger which corresponds to a volume flow rate of $10 \mathrm{l} / \mathrm{min}$ and is equal to the 
volume flow rate on the primary side (Fig. 10, Fig. 11). This means that, in the system under consideration, the primary side volume flow rate should be higher than the secondary side volume flow rate of the heat exchanger. In practice, therefore, the circulating pump on the secondary side of the heat exchanger should operate with the minimum efficiency, while the pump on the primary side of the heat exchanger should operate with the maximum efficiency. This implies that it is not possible to apply volume flow rate control during the heat exchanger operation.

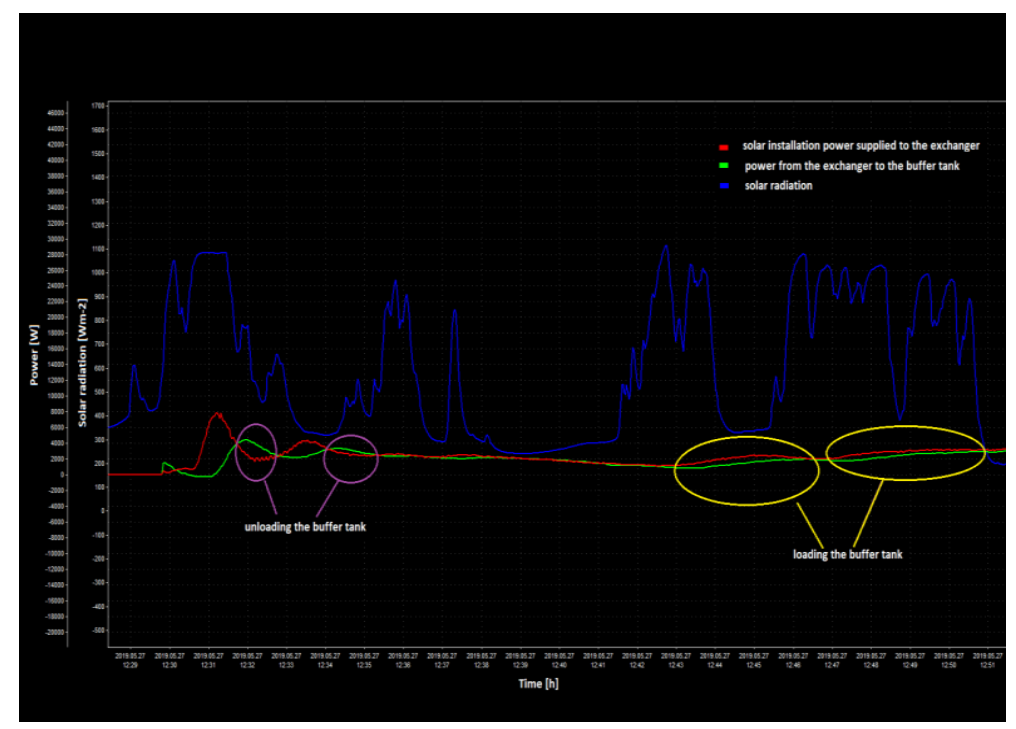

Fig. 10. Power distribution of the primary and secondary sides of the heat exchanger at volume flow rates of $10 \mathrm{l} / \mathrm{min}$ and $10 \mathrm{l} / \mathrm{min}$, respectively.

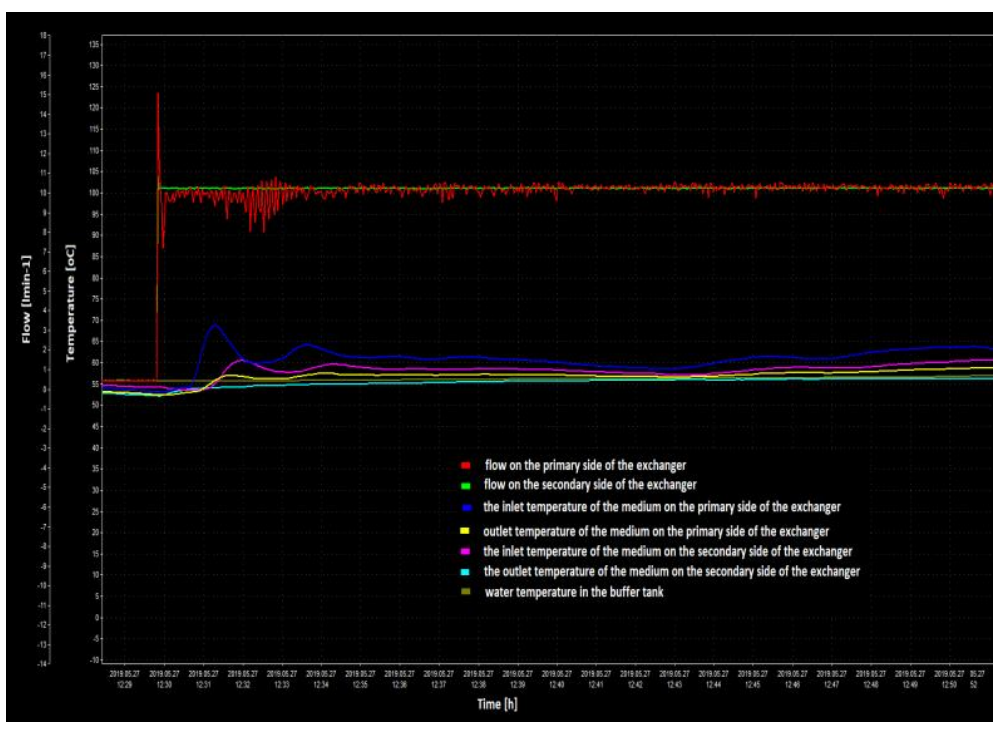

Fig. 11. Temperature distribution on the primary and secondary sides of the heat exchanger at volume flow rates of $10 \mathrm{l} / \mathrm{min}$ and $10 \mathrm{l} / \mathrm{min}$, respectively. 


\section{Conclusions}

The presented analysis shows that the volume flow rate on the primary and secondary sides of the plate heat exchanger has a considerable influence on the heat exchange process. If the volume flow rate of the medium on the secondary side is too high in relation to the volume flow rate on the primary side of the heat exchanger, with a drop of the input power supplied to the primary side of the heat exchanger, the accumulated energy will be dissipated from the buffer storage tank to the environment. In view of the above, it should be concluded that the volume flow rate of the refrigerant on the primary side of the plate heat exchanger should always be greater than the volume flow rate on the secondary side. In the case under consideration, this condition requires replacement of the circulating pump on the heat exchanger primary side with a larger one.

Presented research results were funded from the TESSe2b project, that is financially supported by the Horizon 2020 Research Innovation Action (RIA) of the European Commission, call EeB-Energyefficient Buildings (Grant Agreement 680555).

\section{References}

1. G.V. Gembarzhevskii, J. Eng. Phys. Thermophys. 80, 425 - 439 (2007)

2. P. Obstawski, A. Walczak, COW 5, 188 - 193 (2012)

3. L. Qi, F. Gilles, Y. Xigang, N. Pierre, L. Lingai, Renew. Sust. Energ. Rev. 15, 48554875 (2011)

4. A. Durmus, H. Benli, I. Kurtbas, H. Gul, Int. J. Heat Mass Transf. 52, 1451-1457 (2009)

5. B.P. Rao, S.K. Das, J. Fluids Eng. 126, 680 - 691 (2004)

6. B.P. Rao, B. Sunden, S.K. Das, Appl. Therm. Eng. 26, 1919 - 1926 (2006)

7. C.S. Fernandes, R.P. Dias, J.M. Nobrega, Afonso, L.F. Melo, J.M. Maia, J. Food Eng. 69, 281-290 (2005)

8. S. Fischer, W. Heidemann, H. Müller-Steinhagen, B. Perers, P. Bergquist, B. Hellsotröm, J. Sol. Energy. 76, 117 - 123 (2004)

9. W. Roetzel, X. Luo, Int. J. Heat Mass Transf. 46, 1077-1085 (2010)

10. D. Taler, Int. J. Heat Mass Transf. 40, 809-822 (2004)

11. S. Freund, S. Kabalac, Int. J. Heat Mass Transf. 53, 3764-3781 (2010)

12. S. Ros, C. Jallut, J.M. Grillot, M. Amblard, Int. J. Heat Mass Transf. 38, 1371 - 1325 (1995)

13. M. Lachi, N. El Wakil, J. Padet, Int. J. Heat Mass Transf. 40, 2067-2079 (1997)

14. F.E. Romie, Int. J. Heat Mass Transf. 121, 746-748 (1999)

15. W. Roetzel, Int. J. Heat Mass Transf. 37, 325 - 331 (1994)

16. F. Baguni, H. Chafouk, Int. J. Heat Mass Transf. 42, 835-841 (2006) 